\title{
Plastik termoform prosesinin adaptif yanıt yüzey yöntemi ile eniyilenmesi: Şahlan Plastik firmasında uygulamas1
}

\author{
Aslan Deniz KARAOĞLAN', ${ }^{*}$, Gözde ALICI ${ }^{1}$, Gamze DÜZGÜN1, \\ Sibel Gyunay SALI ${ }^{2}$
}

${ }^{1}$ Balıkesir Üniversitesi, Mühendislik Fakültesi, Endüstri Mühendisliği Bölümü, 10145, Balıkesir, Türkiye

2 Şahlan Plastik Süt Ürünleri Gıda Maddeleri Amb. San. ve Tic.Ltd.Şti., Balıkesir OSB, Balıkesir, Türkiye

Geliş Tarihi (Received Date): 22.04 .2020

Kabul Tarihi (Accepted Date): 07.07.2020

$\ddot{O} z$

Bu çalışmada, plastik termoform süreci eniyilenmesi üzerine çalışılmıştır. Bu amaçla Balıkesir OSB'de faaliyet gösteren Şahlan Plastik firmasinın termoform bardak şekillendirme süreci adaptif yanıt yüzey yöntemi (AYYY) kullanılarak eniyilenmiştir. Bu yöntem kontrol edilebilen değişkenleri ve kontrol edilemeyen değişkenleri birlikte dikkate alarak eniyileme yapan bir yöntemdir. Çalışmanın uygulama aşamasında, 200 ml'lik beyaz ayran bardă̆l üretimi ele alınmıştır. Makine bölge sicaklıkları (4 farklı bölge), kalıp hızl, giriş suyu sicakliğl, ortam sicaklı̆̆l, bobin soğuma saati girdilerine karşılık gözlenen bardak ă̆ırlıkları için 48 adet gözlem değeri alınmıştır. Ağırlık ile ă̆ırlık üzerinde etkili bu faktörler arasındaki ilişki regresyon denklemi ile modellenmiştir. Modelin kullanılabilir olup olmadiğını belirlemek için, belirleme katsayısı $\left(R^{2}\right)$ ve ANOVA analizi sonuçlarına bakılmıştır. Ardından, anlamlı bulunan bu model için $5 \mathrm{gr}$ bardak ă̆ırlı̆̆ını veren eniyilenmiş üretim süreç parametreleri belirlenmiştir.

Anahtar kelimeler: Plastik termoform prosesi, regresyon, adaptif yanıt yüzey yöntemi, eniyileme.

\footnotetext{
*Aslan Deniz KARAOĞLAN, deniz@balikesir.edu.tr, http://orcid.org/0000-0002-3292-5919 Gözde ALICI, gghfalici@ hotmail.com, http://orcid.org/0000-0002-1693-7055

Gamze DÜZGÜN, gamzeeduuzguun@gmail.com, http://orcid.org/0000-0003-0525-8679

Sibel Gyunay SALİ, sibelsali@sahlanplastik.com, http://orcid.org/0000-0003-0154-0554
} 


\title{
Optimization of plastic thermoform process with adaptive response surface methodology: a case study at Sahlan Plastic Co.
}

\begin{abstract}
In this study, optimization of plastic thermoforming process is considered. For this purpose, thermoform cup forming process of Sahlan Plastic Company operating in Ballkesir Industrial Zone was optimized by using Adaptive Response Surface Methodology (ARSM). This method is an optimization method by dealing with controllable variables and uncontrollable variables together. During the application phase of the study, the production of $200 \mathrm{ml}$ white buttermilk glasses was discussed. Zone temperatures (4 different zones), mold speed, inlet water temperature, ambient temperature, coil cooling time are used as the factors, while the cup weights were measured as the output (response) and 48 observation values were taken. The relationship between weight and these factors affecting the weight is modeled with the regression equation. To determine whether the model is significant, the results for the coefficient of determination $\left(R^{2}\right)$ and ANOVA analysis were examined. Then, for this model - which is found to be significant - the optimized production process parameters were determined, giving the weight of $5 \mathrm{~g}$.
\end{abstract}

Keywords: Plastic thermoforming process, regression, adaptive response surface methodology, optimization.

\section{Giriş}

Günümüzde plastik ürünler hemen hemen her alanda yaygın bir şekilde kullanılmaktadır. Extrüderden çıkan plastik levhaların, istenilen kalınlık ölçülerini sağlayacak şekilde termoform prosesi ile şekillendirilmesiyle, müşteri ihtiyaçlarına uygun plastik ürünler elde edilir. Termoform yumuşama noktasına kadar 1sıtılan plastik levhaya 1sı ve basınçla şekil verme sistemidir $[1,2]$.

Plastik ürünlerin imalatında firenin, çevresel etkinin ve maliyetlerin düşürülmesi üzerine birçok çalışma yapılmıştır. $\mathrm{Bu}$ çalışmalar konuyu; kalıp tasarım parametrelerinin, ürün tasarım parametrelerinin veya proses parametrelerinin eniyilenmesi (optimizasyonu) gibi pek çok farklı boyutta ele almıştır. Tang ve ark. [3] çarpılmayı azaltmak için plastik enjeksiyon kalıbının tasarımında Taguchi yöntemini kullanmışlardır. Deformasyondan kaynaklı fireyi en aza indirebilmek amacıyla, eriyik sıcaklığı, doldurma süresi, paketleme basıncı ve paketleme süresi faktörlerinin optimum değerini araştırmışlardır. Karataş ve ark. [4] silindir sıcaklığı, enjeksiyon basıncı, enjeksiyon akış hızı ve kalıp sıcaklığı değişkenlerini ele almış ve yapay sinir ağları ile optimizasyon gerçekleştirmişlerdir. Akyurek ve ark. [5] yeni termoplastik ürünlerin devreye alınma sürecinde yapay sinir ağlarının kullanımı üzerine çalışmışlardır. Volkan ve ark. [6] plastik enjeksiyon prosesinde üründeki çarpılmayı azaltmak amaciyla Taguchi yöntemini kullanmışlar ve uygun kalıp tasarımı yapabilmek amacıyla ürün tasarımı, giriş sayısı, giriş ölçüleri, yolluk tasarımı faktörlerinin eniyilenmesi üzerine çalışmışlardır. Chy ve ark. [7] plastik termoform prosesinde, plastik levha sıcaklığını kontrol etme üzerine çalışmıştır. O'Connor ve ark. [8] termoform şekil verme prosesi eniyilenmesi üzerine çalışmış ve sürtünme, 1sı transferi gibi parametreleri dikkate 
almışlardır. Erdogan ve Eksi [9] termoform prosesinde polipropilen (PP) ve polistiren (PS) plastik levhalar için et kalınlığı dağılımı üzerine çalışmıştır. Kumar ve ark. [10] malzeme karakteristiğinin ve kalıp parametrelerinin ince polipropilen levhaların termoform süreci üzerindeki etkisini incelemişlerdir. Ghobadnam ve ark. [11] yüksek etkili polistiren levhaların termoform süreci üzerine çalışmışlar ve levhaların kalınlık dağılımını gözlemlemişlerdir. Oktariani ve ark. [12] plastik levha şekillendirme prosesi eniyilenmesi için süreç üzerinde etkili katman sayısı, sıcaklık, süre ve basınç faktörlerinin eniyilenmiş değerlerini bulmak amacıyla bulanık mantıktan yararlanmışlarıdır. Leite ve ark. [13] vakum termoforming prosesi üzerine çalışmışlar ve polistiren (PS) hammaddesiyle üretilen plastik ürünlerin boyutsal ve geometrik hatalarını kesirli tam faktöriyel tasarım kullanarak enküçüklemeye çalışmışlardır. Landsecker ve Bonten [14] simülasyondan yararlanarak isı iletken plastik malzemelerin termoform prosesi üzerine çalışmıştır. Dobah ve ark. [15] keten takviyeli polipropilen kompozit malzemelerin termoform süreci üzerine çalışmıştır. Sıcaklık, kalma süresi, basınç ve fabrikasyon alanına ait parametrelere karşılık keten/PP laminatların mekanik ve estetik performansında nem emilimini incelemişlerdir.

Bu çalışmada ise gıda sektörünün ihtiyaçları doğrultusunda plastik ürünler üreten bir firmada, kalıplama yöntemi olarak basınçlı termoform kullanan ayran bardağı üretim prosesi ele alınmıştır. Amaç, istenilen ürün ağırlığını elde edebilmek amacıyla, termoform bardak şekillendirme makinesinin bilgisayar kontrollü üretim parametrelerinin; adaptif yanıt yüzey yöntemi (AYYY) [16] kullanarak optimize edilmesi ve istenilen ağırlıkta ve kalitede ürün üretiminin gerçekleştirilmesidir. Literatürde plastik termoform plastik şekil verme süreç parametrelerinin eniyilenmesi amacıyla AYYY kullanan bir çalışmaya rastlanmamıştır ve bu yönüyle çalışma yenilik içermektedir. Ayrıca çalışmada kullanılan faktör kombinasyonu da daha önceden denenmemiştir ve çalışmanın diğer bir yenilikçi yönüdür. Çalışmanın motivasyonu; 200 ml'lik beyaz ayran bardağının basınçlı plastik termoform süreci ile üretiminde, $5 \mathrm{gr}$ ağırlığında bardaklar üretebilmek için hangi süreç parametrelerinin dikkate alınması gerektiği ve bunların hedef değer üzerindeki etkileri üzerine sektörel bilgi birikimine katkı sağlamaktır.

\section{Yöntem}

\subsection{Regresyonla modelleme ve yanit yüzey yöntemi}

Deney tasarımı yöntemleri, girdiler ile çıtılar arasındaki matematiksel ilişkiyi belirlemeyi ve bu ilişkiyi kullanarak istenilen hedef çıktı değerini sağlayan girdi parametrelerinin değerlerini bulmayı amaçlar. Yaygın olarak kullanılan deney tasarımı yöntemleri yanıt yüzey yöntemi (YYY), faktöriyel tasarım ve Taguchi yöntemidir. Taguchi yöntemi sinyal/gürültü $(\mathrm{S} / \mathrm{N})$ oranı adı verilen ve kontrol edilebilen değişkenlerin çıktı üzerindeki etkisini, kontrol edilemeyen değişkenlerin çıktı üzerine olan etkisine oranlayarak kararlı sistemler tasarlamak için faktör değerlerini arayan bir yöntemdir. Taguchi yönteminde seçilen faktörler nicel olabileceği gibi nitel değişkenlerde olabilir, faktör seviyelerinin eşit olmasına gerek yoktur ve çok az sayıda deney gerektirir. Bunlar Taguchi yönteminin avantajları olmakla birlikte, dezavantaj1 eniyilenmişs sonucu değil eniyilenmiş sonuca yakın bir değer vermesidir. Bir diğer yaygın kullanılan deney tasarımı yöntemi ise faktöriyel tasarım yöntemidir. $\mathrm{Bu}$ yöntemde de faktörler nicel veya nitel olabilir ancak faktörler sadece 2 seviyeli olabilir. Taguchi yönteminin tersine faktöriyel tasarımda girdiler ile çıktılar arasındaki ilişki 
matematiksel olarak regresyon denklemi ile modellenebilir. Regresyon denkleminin lineer regresyon olması gerekir, doğrusal olmayan ilişkileri modellemek ve eniyilemek için uygun bir yöntem değildir. YYY'de ise sadece nicel değişkenler için modelleme yapılabilir. Diğer iki yönteme göre çok daha fazla deney sonucuna ihtiyaç duymakla birlikte, doğrusal olmayan ilişkiler içeren sistemleri modellemekte ve eniyilemekte etkili bir araçtır. YYY'nin matematiksel formülü Denklem (1)'de verildiği gibidir [1621]:

$Y=\beta_{0}+\sum_{i=1}^{n} \beta_{i} X_{i}+\sum_{i=1}^{n} \beta_{i i} X_{i}^{2}+\sum_{i<j}^{n} \beta_{i j} X_{i} X_{j}+\varepsilon$

Burada $Y$ çıktıyı, $X_{i}$ girdi değişkenlerini (faktörler), $X_{i} X_{j}$ çarpımları değişkenler arasındaki etkileşimleri; $\beta$ katsayıları model parametrelerini, $\varepsilon$ ise hata terimini göstermektedir. Regresyon denkleminin içermesi gerektiği terimlere karar verildikten sonra (lineer, lineer+karesel, lineer+etkileşim terimleri, veya tam karesel) $\beta$ katsayılarının hesaplanması gerekir. Minitab deney tasarımı modülü (DOE) ile yapılan analizlerde regresyon denkleminin hangi terimlere sahip olması gerektiği kullanıcıya sorulmaktadır. Buna cevap verebilmek için, eniyileme yapılacak sistemin mekanizması hakkında bilgi sahibi olmak faydalı olacaktır. Aşağıda Denklem (2)'de $\beta$ katsayılarının nasıl hesaplandığı gösterilmektedir:

$\beta=\left(X^{T} X\right)^{-1}\left(X^{T} Y\right)$

Burada $\mathbf{Y}$ çıktı vektörünü, $\mathbf{X}$ girdi matrisini, $\boldsymbol{\beta}$ model parametrelerini gösteren vektörü temsil etmektedir. YYY'nin üzerine geliştirilen ve çok sayıda kontrol edilemeyen değişkenlerinde üretim sistemini etkilediği problemler için önerilen AYYY'de ise; ele alınan bu regresyon denkleminin girdi matrisi, kontrol edilebilen değişkenlerin yanında kontrol edilemeyen değişkenleri de içermektedir. Y vektörü, gözlenen çıktı değerlerinin yer aldığ 1 bir sütun vektördür. $X$ ise bir matristir. $X$ matrisinin 1 . sütunu sabit terimi $\left(\beta_{0}\right)^{\prime} 1$ temsil etmek üzere 1'ler sütunundan oluşmaktadır. $\mathrm{X}$ matrisinin diğer sütunları ise Denklem (1)'de verilen sırada faktör değerlerinden oluşur. Bu çalışmada ele alınan problemi çözmek amaciyla izleyen Bölümde görüleceği üzere 48 gözlem değeri alınmıştır. Dolayısıyla X matrisi 48 satırdan oluşur. Denklemde verilen $\mathrm{T}$ transpoz alma işlemini ifade etmektedir [17-20]. Regresyon denklemi bulunduktan sonra iki tane önemli analiz yapılması gerekir. Bunlar: $(i)$ Belirleme Katsayısı $\left(R^{2}\right)$ hesaplamak, $(i i)$ Varyans Analizi (ANOVA). $R^{2}$ matematiksel denklemde yer alan $X$ parametrelerinin $Y$ 'deki değişimi açıklamak için yeterli olup olmadığını test etmek için kullanılır. $R^{2}$ değeri 1 (\%100)'e yakınsa parametre sayısı yeterlidir. $R^{2}$ düşük ise veri toplama aşamasına dönerek, yeni $X$ değişkenlerine ait veri toplamak ve sonrasında regresyon denklemini bu yeni faktörleri de dâhil ederek yeniden kurmak gerekir. $R^{2}$ 'nin denklemi aşağıda Denklem (3)’te verildiği gibidir:

$R^{2}=\frac{\beta^{T} X^{T} Y-n \bar{Y}^{2}}{Y^{T} Y-n \bar{Y}^{2}}$

$R^{2}$ kabul edilebilir bir değer olarak bulunduysa, sıradaki işlem ANOVA'dır. ANOVA ile F-testi yardımıyla modelin anlamsız olduğunu iddia eden $\mathrm{H}_{0}$ hipotezine karşı, modelin anlamlı olduğunu iddia eden $\mathrm{H}_{1}$ hipotezi test edilir. $\mathrm{Bu}$ amaçla gözlem değerlerinden hesaplanan $\mathrm{F}$ değeri ile istatistiksel tablolardan serbestlik derecelerine göre ( $m$ : modeldeki $\beta$ katsayılarının sayısı, $N$ : gözlem sayısı) bulunabilecek F-kritik değeri kıyaslanır. Eğer $\mathrm{F}>\mathrm{F}$-kritik ise $\mathrm{H}_{1}$ kabul edilir ve model anlamlı demektir. Bir 
diğer yol ise $\mathrm{P}$ değeri yaklaşımıdır. \%95 güven düzeyinde (I.tip hata olasılı $\breve{g} l=\alpha=$ $\% 5=0,05)$, hesaplanan $\mathrm{P}$ değeri $<0,05$ ise model anlamlı demektir. ANOVA tablosu aşağıda Tablo 1'de verildiği gibidir [17]:

Tablo 1. ANOVA tablosu.

\begin{tabular}{|c|c|c|c|c|}
\hline Değişimin kaynağı & $\begin{array}{c}\text { Serbestlik } \\
\text { Derecesi }\end{array}$ & $\begin{array}{c}\text { Kareler } \\
\text { Toplamı }(K T)\end{array}$ & $\begin{array}{c}\text { Kareler Ortalaması } \\
(K O)\end{array}$ & $\mathrm{F}$ \\
\hline Regresyonla Açıklanan (işletim) & $m-1$ & $K T_{\text {Islletim }}$ & $K O_{\text {Isletetim }}=K T_{\text {Islletim }} /(m-1)$ & \multirow[t]{2}{*}{$\mathrm{F}=K O_{\text {Isletetim }} / K O_{\text {Hat }}$} \\
\hline Regresyonla Açıklanamayan (Hata) & $N-m$ & $K T_{\text {Hata }}$ & $K O_{\text {Hata }}=K T_{\text {Hata }} /(N-m)$ & \\
\hline
\end{tabular}

ANOVA sonunda modelin anlamlı bulunması, elde edilen regresyon denkleminin eniyileme amacıyla kullanılabileceğini gösterir. Bu çalışmada "Minitab Response Optimizer" modülü kullanılarak regresyon denkleminin temsil ettiği yanıt yüzeyi üzerinde arama yapılmıştır. Arama algoritması olarak Minitab "Gradient Search" metodunu kullanmaktadır. AYYY ile optimizasyon yaparken öncelikle optimizasyon yapılacak zaman kesitinde, regresyon denkleminde yer alan kontrol edilemeyen değişkenlerin değerleri bulunarak regresyon denkleminde yerine konur. Böylelikle denklem eskiden kontrol edilebilen ve kontrol edilemeyen değişkenleri aynı anda içeriyorken, artık sadece kontrol edilebilen değişkenlerden oluşur. Bu yeni denkleme daha sonra "Gradient Search" uygulanarak istenilen hedef çıktı değerini veren faktör değerleri hesaplanır.

\subsection{Ele alınan üretim sistemi}

$\mathrm{Bu}$ çalışma Balıkesir Organize Sanayi Bölgesinde faaliyet gösteren Şahlan Plastik (Şahlan Plastik Süt Ürünleri Gıda Maddeleri Ambalaj San. ve Tic. Ltd. Şti.) firmasında gerçekleştirilmiştir. Şahlan plastik, plastik sanayinde faaliyet gösteren bir işletme olup kuruluş amacina uygun olarak polipropilen (PP) ve polistiren (PS) hammaddeleri kullanarak gıda ürünleri için ambalaj üretimi yapmaktadır. İşletmenin ana ürün gruplarını ayran bardağ 1 , yoğurt kabı ve tatlı kâsesi oluşturmaktadır. Ayran bardağı ve yoğurt kabı üretiminde ana hammadde olarak PP kullanılırken, tatlı kâsesinde PS kullanılmaktadır. $\mathrm{Bu}$ çalışmada süt ürünleri gıda ambalajlanmasında kullanılan PP hammaddesinden imal edilmiş ayran bardağının üretim süreci ele alınmış ve extrüzyon prosesi sonunda üretilen PP plastik levhalar kullanılarak bilgisayar kontrollü termoform makinesi ile gerçekleştirilen beyaz ayran bardağı üretim süreci optimize edilmeye çalışılmıştır.

Şahlan Plastik’te üretim süreci, plastik levha üretimi ile başlar. $\mathrm{Bu}$ amaçla gerekli hammaddelerin belirlenmiş reçetelere göre karışımları hazırlanır. Bu karışım extrüder hattından geçip bobin haline gelir. Bobin kalite kontrolden geçer ve barkodlanıp depolanır. Bobinin termoform makinesine (sıcak şekil verme makinesi) takılmadan önce belirli bir süre soğuması gerekir. Yeterince soğumadan takılan bobin iyi şekil alamazsa fire oluşmasına sebep olur. Bu yüzden bobinin yeterince soğuması önemli bir detaydır ancak bu ortam sıcaklığından etkilendiği için süreye ait net bir alt sınır vermek zordur. Seri imalat koşulları ve termin tarihi kısıtları altında bobinlerin soğuma süresi önemli bir zaman kısıtını da beraberinde getirmektedir. Bobinin çok uzun süre soğutma amacıyla kenarda bekletilmesi ise; termin süresi kısıtları ve müşteri talepleri göz önüne alındığında önemli bir üretim kısıtıdır. Sonrasında bobinler, termoform makinesine yerleştirilir. Büyük boyutta, ince etli ve hafif levhalar termoform işlemi için uygundur. Termoform ısıtma ve şekillendirme olmak üzere iki adımdan oluşur. Plakanın istenilen 
seviyede yumuşatılması için gerekli ısıtma süresi polimere, levha kalınlığına ve plastiğin rengine bağlıdır. Isıtılan plaka konkav kalıp (dişi) içerisine veya pozitif kalıp (erkek) boşluğu içerisine yerleştirilerek çoğunlukla vakumlu termoform, basınçlı termoform ve mekanik termoform yöntemlerinden biri ile plastik ürüne şekil verme işlemi yapılır [2].

$\mathrm{Bu}$ çalışmada ele alınan şekilleme makinesi K70 termoform bardak şekilleme makinesi'dir. Bu makine basınç ve sıcaklık etkisiyle çalışır (basınçlı termoform yöntemi) ve otomatik dizicileri mevcuttur. Kullanıcı ekranı üzerinden üretim parametrelerinin değerlerini ayarlamak ve takip etmek mümkündür. Üretim sürecinin kaba iş akışı aşağıda Şekil 1'de verilmiştir.

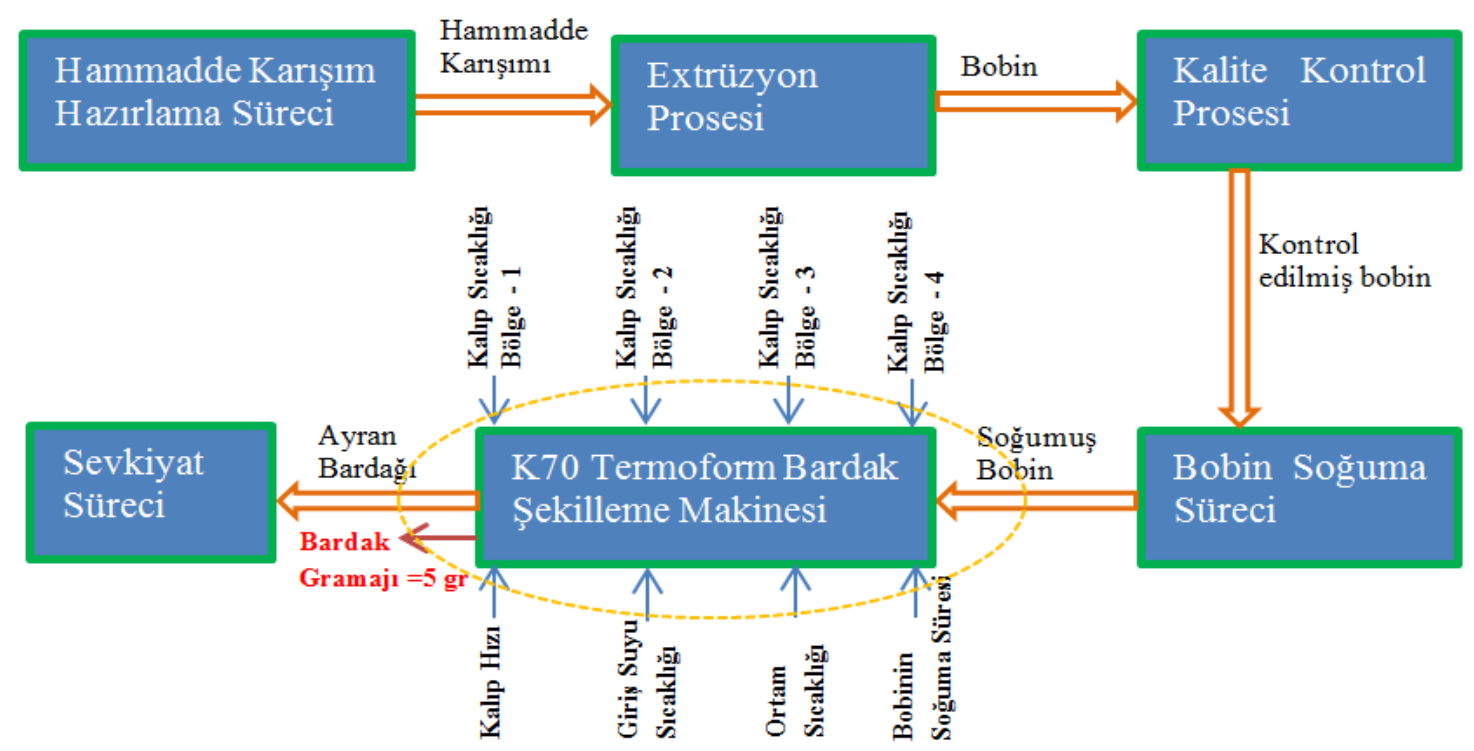

Şekil 1. Ayran bardağı üretim süreci.

K70 termoform bardak şekilleme makinesine ait görseller Şekil 2'de verilmiştir. Bobin termoform sürecine alındığında Şekil 2(a)'da görüldüğü gibi makineye bağlanır ve ardından hız ve sicaklık ayarları yapılır. Makinenin üretim parametreleri Şekil 2(b)'de görülen ekran üzerinden yapılır.

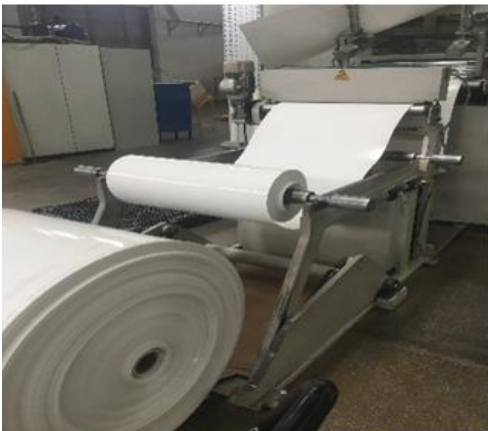

(a)

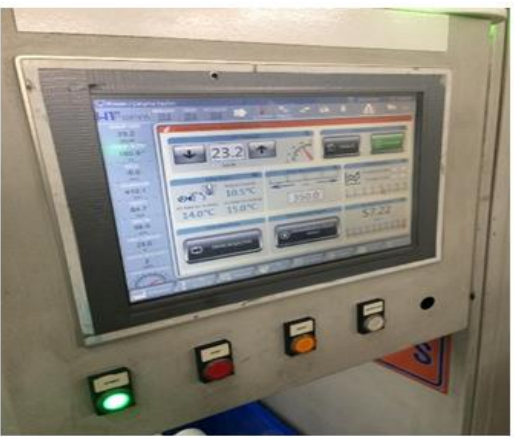

(b)

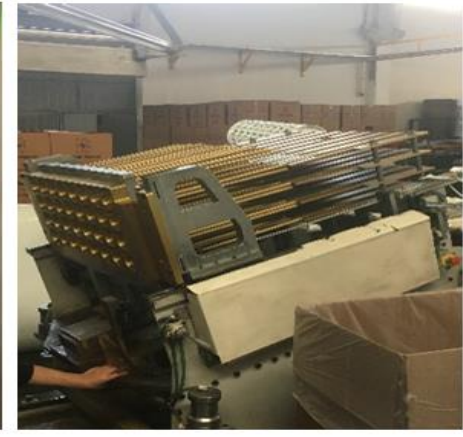

(c)

Şekil 2. K70 termoform bardak şekilleme makinesine ait görseller.

Optimize edilecek bu ayarların detayları makalenin bir sonraki bölümü olan uygulama bölümünde verilecektir. Bardaklar Şekil 2(c)'de görüldüğü gibi, 8 sira ve 4 sütun 
halinde makineden çıkar. Ayran bardağının homojen olması, bardak ağzında deformasyon olmaması ile gramajların eşit ve istenilen değerde olması önemli kalite karakteristikleridir. $\mathrm{Bu}$ çalışmada homojenliği düzgün olan ve bardak ağzında deformasyon olmayan ürün numuneleri arasından seçilen örneklem kullanılarak; diğer önemli bir kalite karakteristiği olan 5 gr ağırlığında bardak üretimi gerçekleştirebilmek için termoform proses parametrelerinin ne olması gerektiği araştırılmıştır. Bu amaçla 200 ml'lik beyaz bardak üzerinde çalışılmış ve farklı şekillendirme parametre değerleri için seri imalat devam ederken veri toplanarak izleyen bölümdeki AYYY ile eniyilenme çalışması gerçekleştirilmiştir. Uygulama bölümünde seçilen parametre aralığı, seçilen numunelerin homojenliğinin uygun ve bardak ağzı deformasyonun olmadığı uygun çözüm uzayını (feasible region) oluşturmaktadır.

\section{Uygulama}

Bu çalışmada 5 gr ağırlığında 200 ml'lik beyaz ayran bardağı üretebilmek amacıyla, PP beyaz plastik levhaların bilgisayar kontrollü termoform prosesi ile şekillendirilme süreç parametrelerinin eniyilenmesi üzerine yoğunlaşılmıştır. Çalışma boyunca ölçülmüş ve süreç üzerinde etkili kontrol edilebilen ve kontrol edilemeyen faktörler ve gözlem boyunca bunlara ait kaydedilen enküçük ve enbüyük değerler aşağıda Tablo 2'de verildiği gibidir:

Tablo 2. Ürün gramajı üzerinde etkili faktörler.

\begin{tabular}{|c|c|c|c|c|c|}
\hline Faktör Ad1 & Kisaltma & Birimi & Değișken Tipi & Min. & Maks. \\
\hline Üst Kalıp Sicaklığı-Bölge 1 & $X_{1}$ & ${ }^{\circ} \mathrm{C}$ & Kontrol Edilebilen & 440 & 452 \\
\hline Üst Kalıp Sicaklığı-Bölge 2 & $X_{2}$ & ${ }^{\circ} \mathrm{C}$ & Kontrol Edilebilen & 427 & 443 \\
\hline Üst Kalıp Sıcaklığı-Bölge 3 & $X_{3}$ & ${ }^{\circ} \mathrm{C}$ & Kontrol Edilebilen & 430 & 445 \\
\hline Üst Kalıp Sicaklığı-Bölge 4 & $X_{4}$ & ${ }^{\circ} \mathrm{C}$ & Kontrol Edilebilen & 442 & 454 \\
\hline Kalıp Hızı & $X_{5}$ & adet/dk & Kontrol Edilebilen & 22,7 & 23,4 \\
\hline Giriș Suyu Sicaklığ & $X_{6}$ & ${ }^{\circ} \mathrm{C}$ & Kontrol Edilebilen & 10,4 & 13,5 \\
\hline Ortam Sicaklı̆̆ 1 & $X_{7}$ & ${ }^{\circ} \mathrm{C}$ & Kontrol Edilemeyen & 13 & 26 \\
\hline Bobin Soğuma Süresi & $X_{8}$ & saat & Kontrol Edilebilen & 7 & 24 \\
\hline
\end{tabular}

Standart deney tasarımı ile modelleme ve eniyileme sürecinde, faktörler ve seviyeleri belirlendikten sonra ortogonal dizilere dayalı deney tasarımı yapılarak gözlenecek faktör değerlerinin kombinasyonlarının önceden belirlenmesi gerekir. Ardından kontrollü olarak her bir deney kombinasyonu için çıktı değeri ölçülür. Ancak çalışma üretimin devam ettiği sürekli akış özelliğinde bir sistemde gerçekleştirilmiş olup, üretimin akışının bozulmaması için girdi değerleri ve buna karşılık gözlenen çıktı değeri üretim devam ederken ölçülmüş ve anlık olarak kaydedilmiştir. Bu amaçla üretim sisteminden 48 farklı değişken kombinasyonuna ait gözlem değerleri $\left(Y_{i}\right)$ alınmıştır. 
Tablo 3. Termoform makinesinden alınan gözlem değerleri.

\begin{tabular}{|c|c|c|c|c|c|c|c|c|c|c|}
\hline Gözlem No & $X_{1}$ & $X_{2}$ & $X_{3}$ & $X_{4}$ & $X_{5}$ & $X_{6}$ & $X_{7}$ & $X_{8}$ & $Y_{i}$ & $\widehat{Y}_{i}$ \\
\hline 1 & 440 & 430 & 431 & 443 & 23,1 & 11,2 & 23 & 14 & 5,03 & 5,0533 \\
\hline 2 & 440 & 430 & 431 & 443 & 23,1 & 11,2 & 23 & 14 & 5,06 & 5,0533 \\
\hline 3 & 440 & 430 & 431 & 443 & 23,1 & 11,2 & 23 & 14 & 5,07 & 5,0533 \\
\hline 4 & 440 & 427 & 430 & 443 & 23,3 & 11,2 & 23,3 & 14 & 5,11 & 5,1167 \\
\hline 5 & 440 & 427 & 430 & 443 & 23,3 & 11,2 & 23,3 & 14 & 5,11 & 5,1167 \\
\hline 6 & 440 & 427 & 430 & 443 & 23,3 & 11,2 & 23,3 & 14 & 5,13 & 5,1167 \\
\hline 7 & 442 & 432 & 433 & 445 & 23,3 & 10,8 & 22 & 15 & 5,11 & 5,1567 \\
\hline 8 & 442 & 432 & 433 & 445 & 23,3 & 10,8 & 22 & 15 & 5,18 & 5,1567 \\
\hline 9 & 442 & 432 & 433 & 445 & 23,3 & 10,8 & 22 & 15 & 5,18 & 5,1567 \\
\hline 10 & 442 & 432 & 433 & 445 & 23,1 & 11,1 & 23 & 14 & 5,18 & 5,2600 \\
\hline 11 & 442 & 432 & 433 & 445 & 23,1 & 11,1 & 23 & 14 & 5,3 & 5,2600 \\
\hline 12 & 442 & 432 & 433 & 445 & 23,1 & 11,1 & 23 & 14 & 5,3 & 5,2600 \\
\hline 13 & 442 & 432 & 433 & 445 & 23,1 & 11,1 & 22 & 14 & 5,06 & 5,0600 \\
\hline 14 & 442 & 432 & 433 & 445 & 23,1 & 11,1 & 22 & 14 & 5,06 & 5,0600 \\
\hline 15 & 442 & 432 & 433 & 445 & 23,1 & 11,1 & 22 & 14 & 5,06 & 5,0600 \\
\hline 16 & 440 & 430 & 435 & 445 & 23,2 & 10,5 & 25 & 24 & 5,06 & 5,1033 \\
\hline 17 & 440 & 430 & 435 & 445 & 23,2 & 10,5 & 25 & 24 & 5,12 & 5,1033 \\
\hline 18 & 440 & 430 & 435 & 445 & 23,2 & 10,5 & 25 & 24 & 5,13 & 5,1033 \\
\hline 19 & 444 & 434 & 435 & 447 & 23,2 & 10,8 & 22 & 15 & 5,07 & 5,0767 \\
\hline 20 & 444 & 434 & 435 & 447 & 23,2 & 10,8 & 22 & 15 & 5,08 & 5,0767 \\
\hline 21 & 444 & 434 & 435 & 447 & 23,2 & 10,8 & 22 & 15 & 5,08 & 5,0767 \\
\hline 22 & 440 & 430 & 435 & 445 & 23,2 & 10,5 & 25 & 24 & 5,06 & 5,1033 \\
\hline 23 & 440 & 430 & 435 & 445 & 23,2 & 10,5 & 25 & 24 & 5,12 & 5,1033 \\
\hline 24 & 440 & 430 & 435 & 445 & 23,2 & 10,5 & 25 & 24 & 5,13 & 5,1033 \\
\hline 25 & 444 & 434 & 435 & 447 & 23,2 & 10,8 & 22 & 15 & 5,07 & 5,0767 \\
\hline 26 & 444 & 434 & 435 & 447 & 23,2 & 10,8 & 22 & 15 & 5,08 & 5,0767 \\
\hline 27 & 444 & 434 & 435 & 447 & 23,2 & 10,8 & 22 & 15 & 5,08 & 5,0767 \\
\hline 28 & 444 & 434 & 435 & 447 & 22,9 & 11,1 & 24 & 14 & 5,23 & 5,2333 \\
\hline 29 & 444 & 434 & 435 & 447 & 22,9 & 11,1 & 24 & 14 & 5,23 & 5,2333 \\
\hline 30 & 444 & 434 & 435 & 447 & 22,9 & 11,1 & 24 & 14 & 5,24 & 5,2333 \\
\hline 31 & 442 & 437 & 437 & 447 & 23 & 10,4 & 25 & 24 & 5,08 & 5,0833 \\
\hline 32 & 442 & 437 & 437 & 447 & 23 & 10,4 & 25 & 24 & 5,08 & 5,0833 \\
\hline 33 & 442 & 437 & 437 & 447 & 23 & 10,4 & 25 & 24 & 5,09 & 5,0833 \\
\hline 34 & 442 & 432 & 437 & 442 & 22,8 & 10,7 & 26 & 24 & 5,03 & 5,0367 \\
\hline 35 & 442 & 432 & 437 & 442 & 22,8 & 10,7 & 26 & 24 & 5,04 & 5,0367 \\
\hline 36 & 442 & 432 & 437 & 442 & 22,8 & 10,7 & 26 & 24 & 5,04 & 5,0367 \\
\hline 37 & 446 & 436 & 437 & 449 & 22,8 & 11 & 20 & 14 & 5,22 & 5,2267 \\
\hline 38 & 446 & 436 & 437 & 449 & 22,8 & 11 & 20 & 14 & 5,22 & 5,2267 \\
\hline 39 & 446 & 436 & 437 & 449 & 22,8 & 11 & 20 & 14 & 5,24 & 5,2267 \\
\hline 40 & 446 & 436 & 437 & 449 & 22,8 & 10,9 & 21 & 14 & 5,19 & 5,2033 \\
\hline 41 & 446 & 436 & 437 & 449 & 22,8 & 10,9 & 21 & 14 & 5,21 & 5,2033 \\
\hline 42 & 446 & 436 & 437 & 449 & 22,8 & 10,9 & 21 & 14 & 5,21 & 5,2033 \\
\hline 43 & 444 & 427 & 439 & 449 & 22,7 & 10,6 & 24 & 24 & 5,03 & 5,0400 \\
\hline 44 & 444 & 427 & 439 & 449 & 22,7 & 10,6 & 24 & 24 & 5,04 & 5,0400 \\
\hline 45 & 444 & 427 & 439 & 449 & 22,7 & 10,6 & 24 & 24 & 5,05 & 5,0400 \\
\hline 46 & 452 & 443 & 445 & 454 & 23,4 & 13,5 & 13 & 7 & 5,25 & 5,2667 \\
\hline 47 & 452 & 443 & 445 & 454 & 23,4 & 13,5 & 13 & 7 & 5,27 & 5,2667 \\
\hline 48 & 452 & 443 & 445 & 454 & 23,4 & 13,5 & 13 & 7 & 5,28 & 5,2667 \\
\hline
\end{tabular}


Tablo 3'de verilen gözlem değerleri kullanılarak faktörler ile yanıt (bardak gramajı) arasındaki matematiksel ilişkiyi gösteren regresyon denklemi ve bu denklem kullanılarak tahmin edilen gramaj değerleri ( $\hat{Y}_{i}$ : beklenen de ğer) Minitab istatistiksel analiz programı yardımıyla hesaplanmıştır. Tabloda gözlenen çıktı değerleri ölçüm aletinin hassasiyetinden dolayı 2 haneli olarak ölçülebilmiştir. Minitab yardımıyla tahmin edilen çıktı değerleri ise daha net bir karşılaştırma sunabilmek amacıyla 4 haneli olarak okuyucuya sunulmuştur. Minitab ile hesaplanan regresyon denklemi Denklem (4)'te verildiği gibidir.

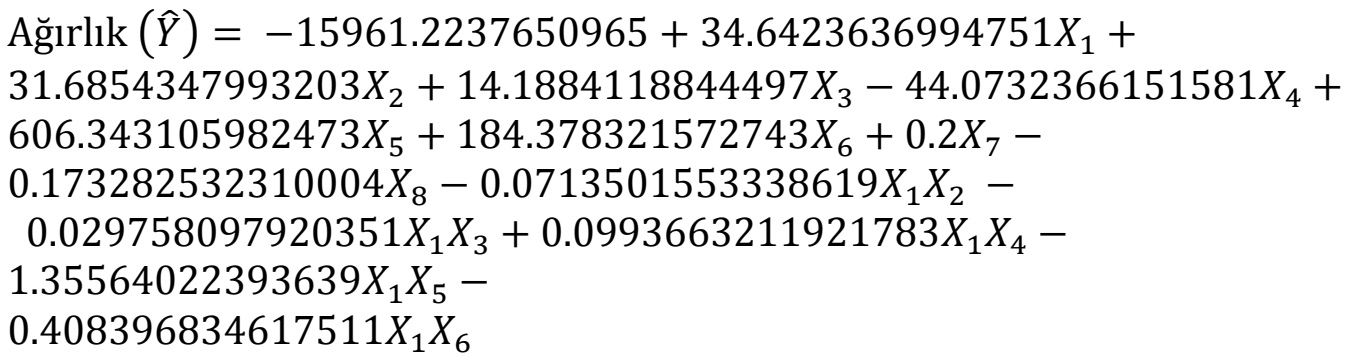

Regresyon denklemlerinin Minitab ile hesaplanan $R^{2}$ değerleri incelendiğinde $R^{2}=\% 93,30 \quad$ (Tablo 3'te verilen 48 adet gözlem değeri için hesaplanan $R^{2}$ ), $R_{\text {Prediction }}^{2}=\% 86,42$ (Minitab'ın kendi içinde yaptığ simülasyonla hesapladığ 1 ve Tablo 3 'te yer almayan değerler için beklenen en düşük tahmin performansı), $R_{\text {Adjusted }}^{2}=\% 90,74$ (regresyon denklemine ait katsayılar için yapılan hipotez testlerine göre, güven aralığı geniş olan - başka bir deyişle güvenilir olmayan - parametreler denklemden çıkarılırsa hesaplanacak olan $R^{2}$ değeri) olarak hesaplanmıştır. Görüldüğü gibi $R^{2}$ değerleri kabul edilebilir olup matematiksel modelde yer alan bu 8 tane faktörün, bardak ağırlığındaki değişimi modellemede yeterli olduğu sonucuna varılmıştır. Minitab ile $\% 95$ (I.tip hata olasıll $\breve{g} l=\alpha=\% 5=0,05$ ) güven düzeyinde hesaplanan ANOVA analiz sonuçları aşağıda Tablo 4'te verildiği gibidir.

Tablo 4. ANOVA sonuçları.

\begin{tabular}{|c|c|c|c|c|c|}
\hline Değişimin kaynağ & $\begin{array}{c}\text { Serbestlik } \\
\text { Derecesi }\end{array}$ & KT & KO & F & P \\
\cline { 1 - 4 } Regresyonla Açıklanan & 13 & 0,296181 & 0,022783 & 36,4 & 0,000 \\
\cline { 1 - 4 } Regresyonla Açıklanamayan (Hata) & 34 & 0,021267 & 0,000625 & \\
\hline
\end{tabular}

Tablo 4'e göre $\mathrm{P}=0,000$ değeri $\alpha=0,05$ değerinden küçük olduğu için (veya hesaplanan $\mathrm{F}$ değeri, istatistiksel F-Tablosundan bakılan kritik değer olan $F_{\alpha, m-1, N-m}=$ $F_{0.05,13,34}=2,0207$ değerinden büyük olduğu için) H1 hipotezi (model anlamlıdır) kabul edilir. Dolayısıyla bu model eniyileme amaciyla kullanılabilir. Bu amaçla “Minitab Response Optimizer" modülünden yararlanılmıştır.

Tablo 2'den de görülebileceği gibi matematiksel modelde yer alan 8 faktörden ilk 6 tanesi termoform makinesi ayarları ile ilgilidir ve operatör tarafından istenilen değere ayarlanabilen (kontrol edilebilen) değişkenlerdir. Bobin soğuma süresi $\left(X_{8}\right)$ aynı şekilde kontrol edilebilen bir değişkendir. Ancak ortam sıcaklığının da belirli bir düzeyde ürün kalitesi üzerinde etkisi olduğu geçmiş tecrübelerden bilinmektedir. Bu nedenle modelde ortam sıcaklığı $\left(X_{7}\right)$ 'de yer almaktadır. Ancak $X_{7}$ kontrol edilemeyen değişkendir. 
Dolayısıyla bu çalışmada literatürde önerilen standart YYY çözümü yerine, ele alınan problemi çözmek amaciyla Karaoğlan ve Çelik tarafindan önerilen AYYY (adaptive RSM) kullanılmıştır [16]. Bu yöntem 3 aşamalı olarak uygulanmaktadır. 1. Aşamada: kontrol edilebilen ve edilemeyen değişkenleri birlikte içerecek şekilde matematiksel model kurulmaktadır; 2. Aşamada: eniyileme yapılacak zaman kesitinde ölçülen kontrol edilemeyen değişken değerleri modelde yerine konarak, sadece kontrol edilebilen değişkenlerden oluşan model elde edilmektedir. 3. Aşamada: yeni elde edilen ve sadece kontrol edilebilen değişkenlerden oluşan model kullanılarak eniyileme tamamlanmaktadır. Mevcut yöntemlerden farkı ise kontrol edilemeyen değişkenlerin değerlerindeki anlık her değişim için optimum sonuç kendisini sürekli yenilemektedir. Dolayısıyla yöntem, kontrol edilemeyen değişkenlerin (bu çalışmada ortam sıcaklığı değişkeni) etkili olduğu üretim sistemlerinde, tek bir optimum yerine sürekli değişen çevresel koşullar altında o anki ortam koşullarına uygun optimum sonuç bulmaya yaramaktadır $[16,19,20]$.

$\mathrm{Bu}$ çalışmada eniyileme yapılacak parti için kontrol edilemeyen değişken olan ortam sıcaklığ $\left(X_{7}\right) 21,6{ }^{\circ} \mathrm{C}$ olarak ölçülmüştür. Ayrıca $\left(X_{8}\right) 15$ saattir soğumakta olan bir bobin kullanılmıştır ve "Minitab Response Optimizer" modülüne bu değer manuel olarak girildikten sonra, bardak gramajı 5 gr olacak şekilde yanıt değişkeninin eniyilenmesi başlatılmış ve Şekil 3 elde edilmiştir.

\begin{tabular}{|c|c|c|c|c|c|c|c|c|}
\hline $\begin{array}{cc} & \text { Yüksek } \\
\text { D } & \text { Orta } \\
0,90325 & \text { Dưsüuk }\end{array}$ & $\begin{array}{c}\mathrm{X} 1 \\
452,0 \\
{[440,0]} \\
440,0\end{array}$ & $\begin{array}{c}X 2 \\
443,0 \\
{[427,0]} \\
427,0\end{array}$ & $\begin{array}{c}X 3 \\
445,0 \\
{[430,0]} \\
430,0\end{array}$ & $\begin{array}{c}X 4 \\
454,0 \\
{[442,0]} \\
442,0\end{array}$ & $\begin{array}{c}\mathrm{X} 5 \\
23,40 \\
{[23,40]} \\
22,70\end{array}$ & $\begin{array}{c}\mathrm{X} 6 \\
13,50 \\
{[11,0]} \\
10,40\end{array}$ & $\begin{array}{c}X 7 \\
26,0 \\
{[21,60]} \\
13,0\end{array}$ & $\begin{array}{c}\mathrm{X} 8 \\
24,0 \\
{[15,0]} \\
7,0\end{array}$ \\
\hline $\begin{array}{c}\text { Toplam } \\
\text { Arzu edilebilirlik } \\
0,90325\end{array}$ & & & & & & & & \\
\hline $\begin{array}{c}Y \\
\text { Hedef: } 5,0 \\
y=5,0048 \\
d=0,90325\end{array}$ & & & & & & & & \\
\hline
\end{tabular}

Şekil 3. "Minitab Response Optimizer" eniyileme grafiği.

Bu sonuçlara göre ortam sicaklığ $1\left(X_{7}\right) 21,6{ }^{\circ} \mathrm{C}$ iken ve 15 saattir soğumakta olan bobin kullanıldığında $\left(X_{8}\right)$; termoform makinesi sirasıyla 4 Bölge sicaklıkları olan $X_{1}=440$, $X_{2}=427, X_{3}=430, X_{4}=442{ }^{\circ} \mathrm{C}$ olarak ayarlanıp, kalıp hızı $X_{5}=23,4$ adet $/ \mathrm{dk}$, giriş suyu sicaklığ $1 X_{6}=11{ }^{\circ} \mathrm{C}$ değerine ayarlanarak $200 \mathrm{ml}$ 'lik beyaz ayran bardağının ağırlığ hedef değer olan 5.0048 gr olarak elde edilmiştir.

\section{Sonuç ve öneriler}

$\mathrm{Bu}$ çalışma, Şahlan Plastik firmasının termoform bardak şekillendirme süreç parametreleri AYYY kullanılarak optimize edilmiştir. Çok sayıda süreç parametresi içeren ve çevresel koşullardan da etkilenen bu sürecin, seri imalat devam ederken deneme yanılmalarla eniyilenmeye çalışılması, hem zaman hem de maliyet açısından zor bir problemdir. Bu amaçla bu çalışmada regresyonla modelleme ve eniyileme üzerine çalışılmıştır. AYYY kontrol edilebilen değişkenleri ve kontrol edilemeyen değişkenleri birlikte dikkate alan bir yöntem olup, plastik termoform prosesi için daha 
önceden uygulanmamıştır. $\mathrm{Bu}$ amaçla 200 ml'lik beyaz ayran bardağının basınçlı plastik termoform süreci ile üretimi ele alınmış ve 5 gr ağırlığında bardaklar üretebilmek için hangi süreç parametrelerinin dikkate alınması gerektiği araştırılmıştır. Süreç parametrelerinin hedef değer üzerindeki etkileri dikkate alınarak eniyileme çalışması gerçekleştirilmiştir. Çalışma sonunda hedef değere ulaşılmıştır. Bu çalışma benzer sürece sahip firmalara, süreçlerini optimize edebilmeleri amaciyla bir yöntem önerisi sunmaktadır. Gelecek çalışmalarda farklı tip ürünler ve farklı renk levhalar kullanılarak çalışma tekrar edilecek ve sonuçlar genişletilecektir.

\section{Teşekkür}

Çalışmaya katkılarından dolayı Şahlan Plastik Süt Ürünleri Gıda Maddeleri Ambalaj San. ve Tic. Ltd. Şti. (Balıkesir - Türkiye) sahibi Ömer VURAL'a ve firma çalışanlarına teşekkür ederiz.

\section{Kaynaklar}

[1] Florian, J., Practical thermoforming principles and applications, 2nd Edition, CRC Press, NY, USA, (1988).

[2] Plastikciyiz.biz.https://www.plastikciyiz.biz/bilgi-kutuphanesi/teknik-bilgikutuphanesi/436/plastik-termoform-prosesi (20.04.2020)

[3] Tang, S. H., Tan, Y. J., Sapuan, S. M., Sulaiman, S., Ismail, N. ve Samin, R., The use of Taguchi method in the design of plastic injection mould for reducing warpage, Journal of Materials Processing Technology, 182, 1-3, 418-426, (2007).

[4] Karataş, Ç., Sözen, A., Arcaklığlu, E. ve Ergüney, S., Modelling of yield length in the mould of commercial plastics using artificial neural networks, Materials and Design, 28, 1, 278-286, (2007).

[5] Akyurek, A., Kece, A., Aksoy, A. ve Ozturk, N., Termoplastik ürünlerin yeni ürün devreye alma sürecinde bir yapay zeka yaklaşımı, Uludă Üniversitesi Mühendislik Mimarlık Fakültesi dergisi, 14, 1, (2009).

[6] Volkan, E., Belevi, M. ve Koçhan, C., Taguchi metodu ile plastik enjeksiyon parçalarda çarpılmanın en aza indirilmesi, DEÜ Mühendislik Fakültesi Fen ve Mühendislik Dergisi, 12, 2, 17-29, (2010).

[7] Chy, M. M. I., Boulet, B. ve Haidar, A., A model predictive controller of plastic sheet temperature for a thermoforming process, Proceedings of the American Control Conference, 4410-4415, (2011).

[8] O'Connor, C. P. J., Martin, P. J., Sweeney, J., Menary, G., Caton-Rose, P. ve Spencer, P. E., Simulation of the plug-assisted thermoforming of polypropylene using a large strain thermally coupled constitutive model, Journal of Materials Processing Technology, 213, 9, 1588-1600, (2013).

[9] Erdoğan, E. S. ve Ekşi, O., Prediction of wall thickness distribution in simple thermoforming moulds, Strojniski Vestnık-Journal of Mechanical Engineering, 60, 3, 195-202, (2014).

[10] Kumar, P. S., Kumar, G. K., Kommoji, S., Banerjee, R. ve Ghosh, A. K., The effect of material characteristics and mould parameters on the thermoforming of thick polypropylene sheets, Journal of Plastic Film \& Sheeting, 30, 2, 162180, (2014). 
[11] Ghobadnam, M., Mosaddegh, P., Rejani, M. R., Amirabadi, H. ve Ghaei, A., Numerical and experimental analysis of HIPS sheets in thermoforming process, International Journal of Advanced Manufacturing Technology, 76, 5-8, 1079-1089, (2015).

[12] Oktariani, E., Istikowati, R., Tomo, H. S. S., Rizal R. ve Pratama, Y., Multi response optimization of sheet forming of kenaf-polypropylene composites using grey based fuzzy algorithm, 3rd International Conference on Industrial, Mechanical, Electrical, and Chemical Engineering (ICIMECE), Article number: UNSP 03000 , Surakarta, Indonesia, (2017).

[13] Leite, W. O., Rubio, J. C. C., Mata, F., Hanafi, I., Carrasco, A., Dimensional and geometrical errors in vacuum thermoforming products: an approach to modeling and optimization by multiple response optimization, Measurement Science Review, 18, 3, 113-122, (2018).

[14] Landsecker, K. ve Bonten, C., Thermoforming simulation of heat conductive plastic materials using the K-BKZ model, Proceedings of PPS-34: The 34th International Conference of the Polymer Processing Society - Conference Papers, 2065, Article Number: UNSP 030049, (2019).

[15] Dobah, Y., Zampetakis, I.,Ward, C. ve Scarpa, F., Thermoformability characterisation of Flax reinforced polypropylene composite materials, Composites Part B - Engineering, 184, Article Number: 107727, (2020).

[16] Karaoglan A. D. ve Celik N., A new painting process for vessel radiators of transformer: wet-on-wet (WOW), Journal of Applied Statistics, 43, 2, 370386, (2016).

[17] Montgomery, D. C., Design and analysis of experiments, 8th ed. John Wiley \& Sons, Inc., NJ, USA, (2013).

[18] Mason, R. L., Gunst, R. F. ve Hess, J. L., Statistical design and analysis of experiments, 2nd ed., John Wiley \& Sons Inc., NJ, USA, (2003).

[19] Karaoglan, A. D., Demir, M. M. ve Çarkacı, M. M., Yonga levha üretim süreçlerinde pres süresinin enküçüklenmesi, Pamukkale Üniversitesi Mühendislik Bilimleri Dergisi, 24, 4, 658-664, (2017).

[20] Karaoglan, A. D. ve Meric, A. Nikel kaplama prosesinde verimli olarak kullanılan nikel oranının yanıt yüzey yöntemi ile eniyilenmesi. Pamukkale Üniversitesi Mühendislik Bilimleri Dergisi, 25, 4, 507-512, (2019).

[21] Krishnaiah, K. ve Shahabudeen, P., Applied Design of Experiments and Taguchi Methods, PHI Learning, New Delhi, India, (2012). 